\title{
Measurement of avocado softening at various temperatures using ultrasound
}

\author{
U. Flitsanov ${ }^{\mathrm{a}, *}$, A. Mizrach ${ }^{\mathrm{b}}$, A. Liberzon ${ }^{\mathrm{a}}$, M. Akerman ${ }^{\mathrm{c}}$, G. Zauberman ${ }^{\mathrm{c}}$ \\ a Faculty of Agricultural Engineering, Technion-Israel Inst. Tech., Haifa 32000, Israel \\ ${ }^{\mathrm{b}}$ Institute of Agricultural Engineering, Agricultural Research Organization (ARO), the Volcani Center, PO Box 6, \\ Bet Dagan50250, Israel \\ ${ }^{\mathrm{c}}$ Institute for Technology and Storage of Agricultural Products, ARO, the Volcani Center, PO Box 6, Bet Dagan 50250, Israel
}

Received 12 October 1999; accepted 19 June 2000

\begin{abstract}
The low-temperature storage of avocado affects its subsequent softening process and shelf life. One of the main indices of ripeness in avocado fruit is firmness, which changes during the ripening and softening process. The temperature and duration of storage fundamentally influence the firmness of the stored fruit, and monitoring the softening of fruit enables us to regulate its shelf life. The objective of the present study was to use nondestructive ultrasonic tests to elucidate the influences of storage temperature and time on the softening process of avocado fruit. The attenuation of the ultrasonic waves transmitted through the fruit tissue changes as the fruit passes through the various softening stages during and after low-temperature storage. Four groups of avocados, each stored at a different low temperature, and a control group which was stored at room temperature $\left(20^{\circ} \mathrm{C}\right)$ were examined during and after their designated storage times, until they reached full ripeness at room temperature. Nondestructive ultrasonic tests and destructive penetration measurements were carried out in order to determine the attenuation and the tissue firmness, respectively, of the avocados. Statistical analysis showed quite good correlation between the firmness and the ultrasonic attenuation, and their dependence on previous storage time-temperature history. This suggests that the ultrasonic measurements could be used as a nondestructive method of monitoring avocado ripeness during low-temperature storage. (C) 2000 Elsevier Science B.V. All rights reserved.
\end{abstract}

Keywords: Ultrasonic transducers; Firmness; Temperature measurements; Storage time; Avocado

\section{Introduction}

Horticultural maturity of avocado (Persea americana Mill. cv. 'Ettinger') fruit can be defined

\footnotetext{
* Corresponding author. Tel.: + 972-4-8292802; fax: +9724-8221529.

E-mail address: fltyuri@tx.technion.ac.il (U. Flitsanov).
}

as the growth stage at which harvested fruit will undergo normal ripening. Mature avocados do not ripen on the tree, but soften several days after being picked. When an immature avocado is harvested, it will not ripen properly, if at all, whereas an over-ripe one will decay rapidly after harvest. One of the main indicators of ripening in avocado is their firmness. Previous studies have shown that 
avocado firmness correlates well with fruit ripeness and expected storage time (Lewis, 1978). Firmness declines initially at a moderate rate, which increases later until firmness falls to less than $5 \mathrm{~N}$ resistance of penetration at full ripening (Zauberman and Fuchs, 1981). The temperature and time of storage fundamentally influence the firmness and other mechanical parameters of the stored fruit. The response of avocados to lowtemperature storage has been studied by Bleinroth et al. (1976), Zauberman et al. (1977), Zauberman and Jobin-Decor (1995), Berger et al. (1982), and the firmness change under these conditions has been used as an indicator of ripening. Storage temperatures generally range between 5 and $8^{\circ} \mathrm{C}$, but some research performed as low as $2^{\circ} \mathrm{C}$ found that storage at $2-8^{\circ} \mathrm{C}$ could extend shelf life and facilitate the distribution of avocados to distant markets.

In order to control the ripening process and to ensure longer shelf life, it is advisable to monitor the firmness of the avocado fruit during low-temperature storage. Frequently removing samples of fruit and performing penetrometer tests is a means of doing this, but it is a destructive technique that does not allow continuous monitoring, and there is a great need for a nondestructive method. Various researchers have suggested diverse nondestructive methods for maturity and firmness evaluation of avocado fruit: nuclear magnetic resonance (NMR) methods (Chen et al., 1993), applying vibrations to one side of the fruit, while measuring the transmitted vibration energy on its other side (Peleg et al., 1990), acoustic testing based on mechanical impulse excitation and flexible piezoelectric sensors (commercially available as Firmalon) (Galili et al., 1998); near infrared spectroscopy (Schmilovitch et al., 1997); ultrasonic excitation (Mizrach et al., 1996), etc. None of these studies included measurements at various storage temperatures. The present authors propose an ultrasonic technique for measurements of the avocado softening process under low-temperature storage conditions. An ultrasonic technique has been suggested in the past, as a dedicated method for nondestructive firmness evaluation of fruit and vegetables (Mizrach et al., 1989); it used a high-power, low-frequency ultra- sonic system for excitation of fruit tissue, and exploited the basic acoustic properties of some fruit and vegetables, i.e. wave propagation velocity and attenuation. In addition, Mizrach et al. (1994) found a strong interdependence between ultrasonic properties and post-harvest ripening parameters of the fruit tissue, and they patented a device for nondestructive determination of fruit quality parameters. Models of ultrasonic parameters to assess avocado properties and shelf life were suggested as well (Mizrach et al., 1996). All the above-mentioned studies of the ultrasonic technique were performed on avocados placed in room-temperature storage immediately after harvest. Recently, Mizrach et al. (2000) suggested a method for monitoring avocado softening in lowtemperature storage using nondestructive ultrasonic measurements. The objective of the present study was to use this technique to analyze ultrasonic signals in avocados stored at several low temperatures and to examine the effects of the temperature and storage time on the softening process in the low-temperature storage and while removing the fruit to room-temperature storage.

\section{Materials and methods}

The basic experimental arrangement included a high-power, low-frequency ultrasonic pulser-receiver (Krautkramer, model USL33), a pair of $50-\mathrm{kHz}$ ultrasonic transducers and a microcomputer system for data acquisition and analysis. Exponential-type Plexiglas beam-focusing elements were used to reduce the $55-\mathrm{mm}$ diameter of the beam from each transducer to that of the desired area of contact with the fruit. The transducers were mounted with an angle of $\sim 120^{\circ}$ between their axes, enabling an ultrasonic signal to be transmitted and received over a short distance across the peel of the fruit (Mizrach et al., 1994). The head arrangement allowed relative motion of the ultrasonic probes along a transverse axis, while a controlled contact force on the fruit peel was maintained.

The through-transmission mode was selected, with one transducer acting as a transmitter and the other as a receiver. The pulser caused the 
transmitter to oscillate and emit a narrow-band ultrasonic pulse obliquely into the peel and through the fruit tissue. Previous study had shown that the thin peel of avocado fruit (cv. 'Ettinger') did not interfere with the ultrasonic waves (Mizrach et al., 1994). The ultrasonic energy input induced waves through the fruit tissue, which activated the receiver. The output pulse was displayed on a cathode ray tube (CRT) monitor, on which the pulse amplitude and transit time could be visually determined. In parallel, a built-in peak detector and microprocessor-controlled serial interface captured the signal amplitude and the transit time, and sent a digitized read-out to an external microcomputer. The collected data were used to determine the attenuation of the waves and hence to calculate the attenuation coefficient of the fruit, by means of common formulations described by Mizrach et al. (1989).

Mature avocado (cv. 'Ettinger') were harvested and graded by weight, and those of OECD standard (OECD, 1995) size group '16' (weight between 236 and $265 \mathrm{~g}$ ) were selected. Fruit were transported to the laboratory within $48 \mathrm{~h}$ and transferred to well ventilated rooms at 2, 4, 6 and $8^{\circ} \mathrm{C}$. Fifteen avocados were stored continuously in a ventilated laboratory at $20^{\circ} \mathrm{C}(\sim 85 \%$ humidity); they served as controls and were assessed daily. Each week for 4 weeks, 15 fruit were removed from each temperature regime for ultrasonic nondestructive tests and destructive penetration tests at five successive ripening times. The peel of each fruit was marked at six locations on the circumference ('equator') of the largest cross-section perpendicular to the blossom endstem end axis; one for ultrasonic nondestructive testing and the remaining five for penetration tests at successive ripening times. The six locations were spaced $60^{\circ}$ apart around the circumference, to minimize the influence on the repeated NDT tests and of local bruising caused by the firmness penetration test. Destructive tests were conducted immediately after the ultrasonic tests, to determine the firmness of the avocado fruit.

Each fruit was subjected daily to a nondestructive ultrasonic test. The pulse amplitude of the transmitted ultrasonic signal was measured at the marked point, for five different spacings $(5,12$,
14, 16 and $18 \mathrm{~mm}$ ) between the two probes. The attenuation of the ultrasonic signal was calculated according to the exponential expression (Krautkramer and Krautkramer, 1990): $A=$ $A_{0} \mathrm{e}^{-\alpha l}$, where $l$ is the spacing between the input and collection probes, $A$ and $A_{0}$, respectively, are the ultrasonic signal amplitudes at the beginning and end of the propagation path, $l$ of the ultrasonic wave, and $\alpha$ is the apparent attenuation coefficient of the signal.

The penetration tests were performed on unpeeled fruit (a recognized method for firmness determination in all varieties of avocado fruit), with a durometer (John Chatillon \& Sons, New York) with a $6.35-\mathrm{mm}$ diameter conical head and $60^{\circ}$ cone angle (Mizrach et al., 1996). The peak force, measured in newtons $(\mathrm{N})$, was recorded at a penetration rate of $3 \mathrm{~mm} / \mathrm{s}$, to a maximum penetration depth of $\sim 7 \mathrm{~mm}$. Each fruit was subjected to the penetration test at the remaining marked locations, in sequence, every second day until they reached eating ripeness (i.e. firmness equal to $10 \mathrm{~N}$ ).

\section{Results and discussion}

The softening process of the control avocados $\left(20^{\circ} \mathrm{C}\right)$ started immediately after harvest, and their firmness dropped rapidly from $99.5 \mathrm{~N}$ on the first day to a low value of $12.1 \mathrm{~N}$ after 7 days (Table 1). The ultrasonic attenuation of this group increased rapidly over the same period from 2.09 $\mathrm{dB} / \mathrm{mm}$ initially to $4.03 \mathrm{~dB} / \mathrm{mm}$ on the last day. The correlation coefficient between the attenuation and the firmness for the control avocados was determined once, immediately after storage, and found to be relatively high. A correlation analysis was performed for the controls (15 fruit) and for the totals of the weekly values over 4 weeks (60 fruit per storage temperature).

As shown in Table 1, the avocados at 6 and $8^{\circ} \mathrm{C}$ softened more rapidly than those stored at 2 and $4^{\circ} \mathrm{C}$. During four weeks of storage at the lower temperatures $\left(2\right.$ and $\left.4^{\circ} \mathrm{C}\right)$, the firmness decreased, although insignificantly, to 89.2 and 79.2 $\mathrm{N}$, respectively. Fruit from higher temperature storage (i.e. 6 and $8^{\circ} \mathrm{C}$ ) changed their firmness 
more significantly to 12.5 and $10.9 \mathrm{~N}$, respectively. The attenuation measured on avocados sampled from low-temperature storage initially decreased during the first storage week, and avocados from lower storage temperatures showed lower attenuation. The signal amplitude attenuation changed from an initial value of $2.09 \mathrm{~dB} / \mathrm{mm}$ to lower values: $1.56,1.89,1.94$ and $2.03 \mathrm{~dB} / \mathrm{mm}$, for fruit stored at $2,4,6$ and $8^{\circ} \mathrm{C}$, respectively. This phenomenon has been reported in previous studies (Mizrach et al., 1989; Mizrach and Flitsanov, 1995; Mizrach et al., 1996). Then, from the end of the first week of low-temperature storage until 28 days, the attenuation increased with time for all groups: to $1.87,2.36,3.02$ and $3.19 \mathrm{~dB} / \mathrm{mm}$ for those stored at $2,4,6$ and $8^{\circ} \mathrm{C}$, respectively.
The firmness values and the amplitude attenuation for 4 weeks of low-temperature storage are presented in Fig. 1 as dots connected with dotted lines. The fruit stored at 4 and $6^{\circ} \mathrm{C}$ gave better correlation coefficients between destructive and nondestructive tests $(r=0.978$, and 0.979 , respectively) than those stored at 2 and $8^{\circ} \mathrm{C}(r=0.926$ and 0.9 , respectively).

The second stage of the experiment was the analysis of the ripening process at room temperature $\left(20^{\circ} \mathrm{C}\right)$, after low-temperature storage. After each week, during 4 weeks of cold storage, 15 fruit were removed from each group and kept at room temperature $\left(20^{\circ} \mathrm{C}\right)$ until their firmness reached the ripe level (i.e. $10 \mathrm{~N}$ ). The fruit firmness changes were monitored with nondestructive

Table 1

Variation of wave amplitude attenuation and firmness of avocado, during 4 weeks of low-temperature storage (at $2,4,6$ and $8^{\circ} \mathrm{C}$ ), and control group stored at room temperature $\left(20^{\circ} \mathrm{C}\right)$

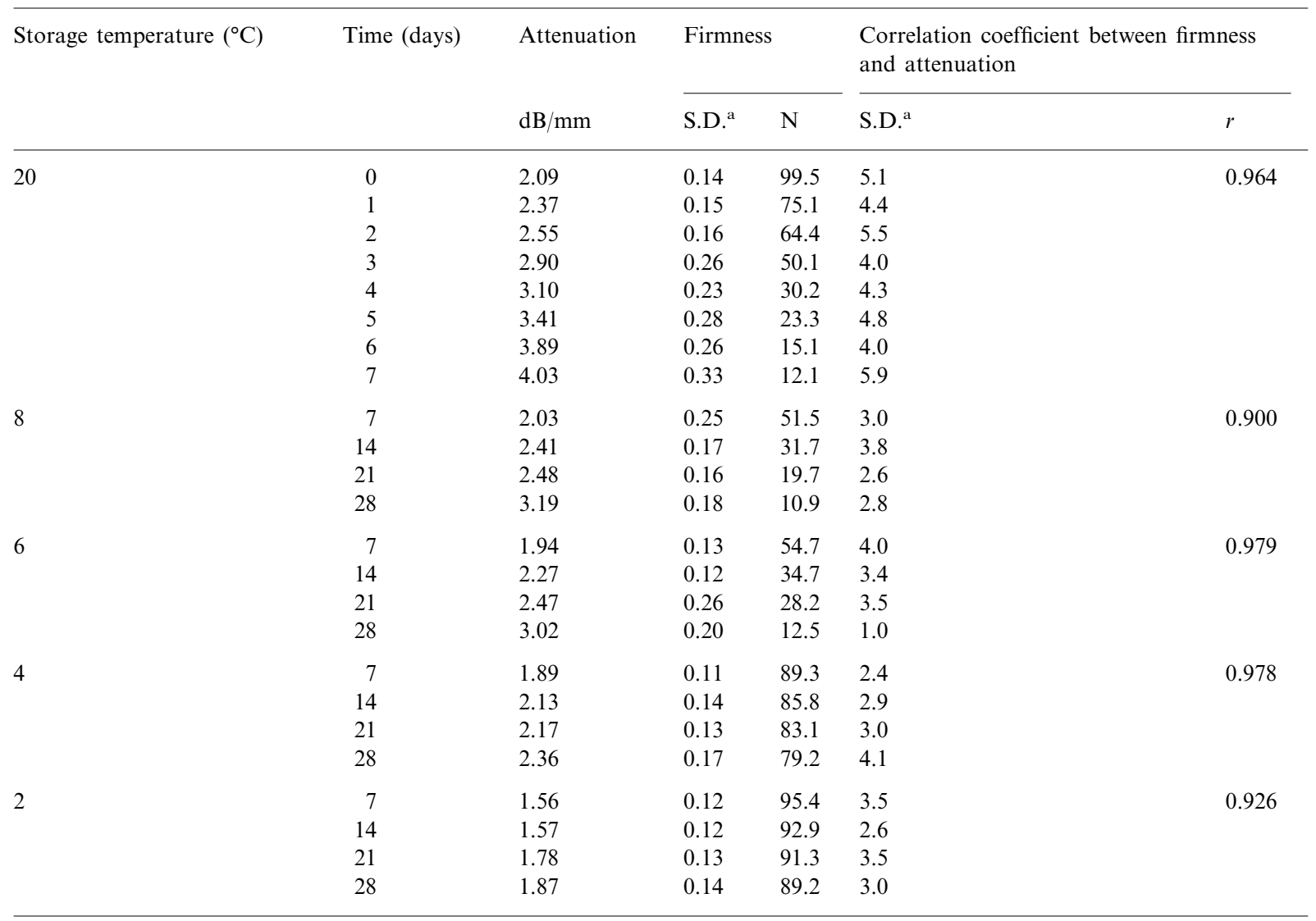

a Standard deviation (S.D.). 

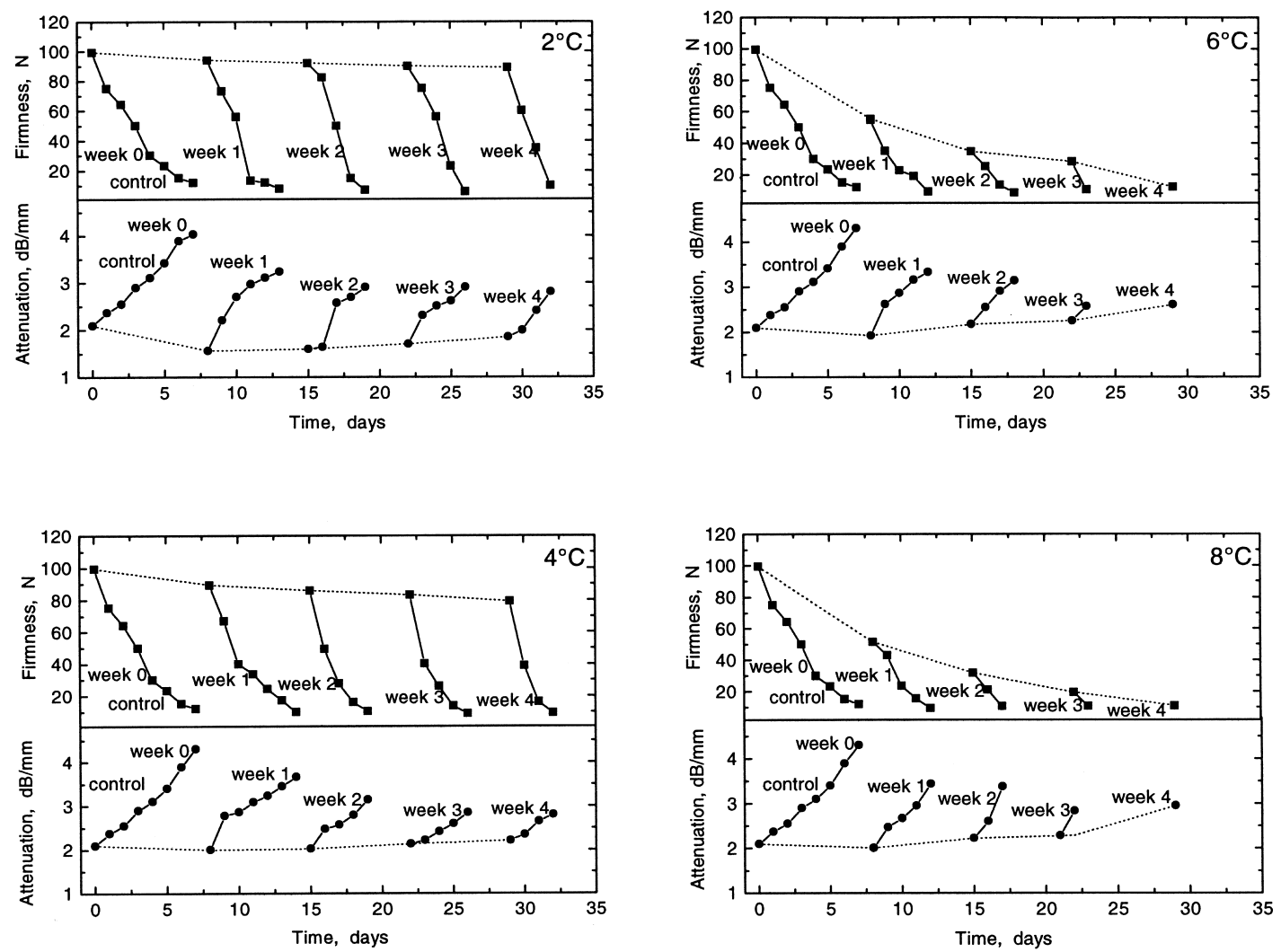

Fig. 1. Variation of the mean values of firmness ( $\mathbf{\square})$ and wave attenuation $(\boldsymbol{)})$ with time at room temperature for avocado removed weekly from $2,4,6$ and $8^{\circ} \mathrm{C}$ storage temperatures. Dotted lines represent the variation with time of the firmness and attenuation during low-temperature storage.

ultrasonic attenuation measurements and measured with the destructive penetration test. The changes with time of the mean values of the resulting firmness and ultrasonic wave attenuation data are presented in Fig. 1. The corresponding data for the control group are also presented in Fig. 1, labeled 'week 0'. Firmness and attenuation data for each sample of fruit were recorded from their removal to room temperature until they reached a firmness of $10 \mathrm{~N}$. The graphs show that the softening process of avocado fruit which had been stored at 2 and $4^{\circ} \mathrm{C}$ was slower than that of those stored at 6 and $8^{\circ} \mathrm{C}$ (Fig. 1). Thus, after the first week of low-temperature storage, the ripening of the fruit stored at 2 and $4^{\circ} \mathrm{C}$ took 7 and 8 days, respectively, while those stored at 6 and $8^{\circ} \mathrm{C}$ ripened faster, taking 5 days. The time data (in days) for room temperature ripening (i.e. shelf life) are presented in Table 2; the ripening time decreased with increasing storage time. Thus, after 3-4 weeks of storage at the higher temperatures, the fruit softening took 2 days or 1 day for fruit stored at 6 or $8^{\circ} \mathrm{C}$, respectively. Avocados stored at $2^{\circ} \mathrm{C}$ for 4 weeks ripened within 3 days, but those stored at $4^{\circ} \mathrm{C}$ took a mean of 4 days to ripen fully. Some of the fruit stored at $2^{\circ} \mathrm{C}$ for 4 weeks sustained chilling injury defects.

In parallel to destructive firmness measurements, nondestructive ultrasonic measurements were performed. Fig. 1 shows that attenuation increased during the ripening at room-temperature, after removal of the avocados from cold storage. A good correlation was found between the firmness and the ultrasonic wave attenuation data presented in Fig. 1, and summarized in Table 3. The correlation coefficients for the groups, 
stored at 2 and $4{ }^{\circ} \mathrm{C}$ and removed after weeks $1-4$ were in the ranges of $0.914-0.973$ and $0.857-$ 0.966 , respectively; for those stored at 6 and $8^{\circ} \mathrm{C}$ and removed after week 1 or 2 , the correlation coefficients were in the range of $0.939-0.998$ or 0.968 , respectively. The coefficients were similar to that calculated for the control group (stored at room temperature), i.e. 0.964 .

Fig. 1 shows that the attenuation measured at full ripeness (firmness of $\sim 10 \mathrm{~N}$ ), diminished as cold-storage time increased, for all temperature groups. Thus, the mean attenuation in the control group was $4.03 \mathrm{~dB} / \mathrm{mm}$ and the firmness was 12.1 $\mathrm{N}$. The avocados stored for 1 week at 2, 4, 6 and $8^{\circ} \mathrm{C}$ and measured after shelf life at room temperature, showed attenuation of $3.23 \mathrm{~dB} / \mathrm{mm}$ for 8.1 $\mathrm{N}, 3.66 \mathrm{~dB} / \mathrm{mm}$ for $9.9 \mathrm{~N}, 3.32 \mathrm{~dB} / \mathrm{mm}$ for $9.2 \mathrm{~N}$ and $3.43 \mathrm{~dB} / \mathrm{mm}$ for $9.5 \mathrm{~N}$, respectively. The corresponding values after 4 weeks of low-temperature storage were $2.80 \mathrm{~dB} / \mathrm{mm}$ for $10.1 \mathrm{~N}, 2.79$ $\mathrm{dB} / \mathrm{mm}$ for $9.4 \mathrm{~N}, 2.60 \mathrm{~dB} / \mathrm{mm}$ for $12.3 \mathrm{~N}$ and $2.95 \mathrm{~dB} / \mathrm{mm}$ for $10.9 \mathrm{~N}$, respectively.

The influence of the various storage temperatures, obtained from discrete storage cells (2, 4, 6 and $8^{\circ} \mathrm{C}$ ), on the firmness and ultrasound attenuation after 1, 2, 3 and 4 weeks was investigated as well, and the results are presented in Fig. 2. A linear expression, Attenuation $=A \times$ Temperature $+B$, was selected as the curve of 'best fit'. The parameters $A$ and $B$, for the linear expression and the coefficient of determination are summarized in Table 4; higher attenuation observed for higher storage temperatures. The incremental rates ( $A$ in Table 4 ) became faster as the storage

Table 2

Days to reach the designated firmness level of $10 \mathrm{~N}$ for fruit stored at room temperature; 15 fruit in each sample

\begin{tabular}{|c|c|c|c|c|c|}
\hline \multirow[t]{3}{*}{ Cold-storage temperature $\left({ }^{\circ} \mathrm{C}\right)$} & \multicolumn{5}{|c|}{ Cold-storage time (weeks) } \\
\hline & 0 & 1 & 2 & 3 & 4 \\
\hline & \multicolumn{5}{|c|}{ Room-temperature storage time (days) } \\
\hline 20 (control) & 8 & - & - & - & - \\
\hline 4 & - & 8 & 7 & 5 & 4 \\
\hline 2 & - & 7 & 5 & 4 & 3 \\
\hline
\end{tabular}

Table 3

Correlation coefficient $(r)$ between firmness and attenuation measured at room temperature $\left(20^{\circ} \mathrm{C}\right)$, for various combinations of previous cold-storage temperature and time ${ }^{a}$

Cold-storage temperature $\left({ }^{\circ} \mathrm{C}\right)$
Cold-storage time (weeks)

\begin{tabular}{llllll}
$\overline{0}$ & \multicolumn{2}{l}{} & & \\
\hline
\end{tabular}

Correlation coefficient between firmness and attenuation at $20^{\circ} \mathrm{C}$ after cold-storage

\begin{tabular}{|c|c|c|c|c|c|}
\hline 20 (control) & 0.964 & - & - & - & - \\
\hline 8 & - & 0.968 & $*$ & $*$ & $*$ \\
\hline 6 & - & 0.991 & 0.998 & $*$ & $*$ \\
\hline 4 & - & 0.966 & 0.947 & 0.857 & 0.936 \\
\hline 2 & - & 0.959 & 0.958 & 0.914 & 0.973 \\
\hline
\end{tabular}

\footnotetext{
${ }^{\text {a }}$ Weekly samples of 15 fruit, 4-week total sampled 60 fruit.

* The correction coefficient between firmness and attenuation has not been calculated due to insufficient amount of data.
} 


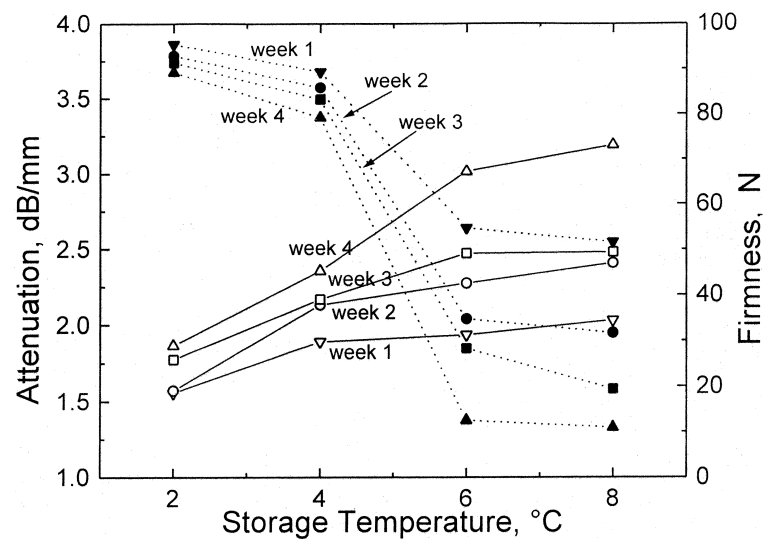

Fig. 2. The variation of the mean values of firmness $(\boldsymbol{\Delta}, 4$ weeks; $\mathbf{\square}, 3$ weeks; $\boldsymbol{\bullet} 2$ weeks; $\boldsymbol{\nabla}, 1$ week) and the ultrasound signal attenuation ( $\triangle, 4$ weeks; $\square, 3$ weeks; $\bigcirc, 2$ weeks; $\nabla, 1$ week) with storage temperatures, at several storage times, for avocado fruit cv. 'Ettinger'.

period increased. Unlike the linear dependence of attenuation, the firmness followed a sigmoidal curve (Fig. 2). A significant change occurred between 4 and $6^{\circ} \mathrm{C}$ for all storage times, for reason(s) as yet unknown, and further study is required. Since firmness and attenuation were both time-dependent, the direct relationship between these two parameters was plotted (Fig. 3). A fundamental relationship between firmness and attenuation could be observed in two clusters. Data from 6 to $8^{\circ} \mathrm{C}$ concentrated in cluster 1 and those from 2 to $4^{\circ} \mathrm{C}$ concentrated in cluster 2 (Fig. 3 ). This suggests that monitoring of fruit firmness by means of attenuation measurements should be differentiated, at least between storage above and below $6^{\circ}$. However, for a given storage temperature, the results appear to suggest that the ultrasonic method can be used as a nondestructive

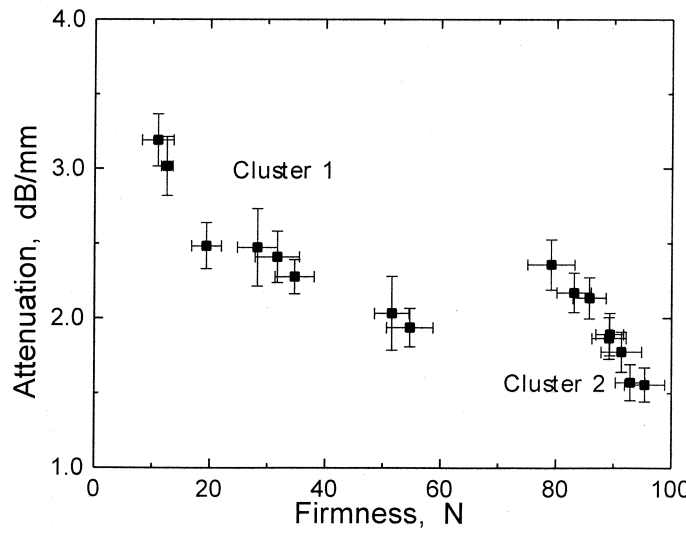

Fig. 3. The relations between the ultrasound signal attenuation and the firmness of the avocado, independently of the temperature and storage period of time. Vertical and horizontal lines represent confidence limits.

firmness monitoring technique during low-temperature storage.

\section{Summary and conclusions}

This study demonstrated the possibility of using an ultrasonic measurement technique for nondestructive monitoring of the softening process in avocado, during and after low-temperature storage at various temperatures. Ultrasonic attenuation was negatively related to the measured firmness of the stored fruit and to their ripening stage. The wave attenuation measured during low-temperature storage increased with time, while the firmness of the fruit decreased at different rates for different storage temperatures, and these rates were positively correlated with the attenuation. It is suggested that the ultrasonic

\section{Table 4}

Parameters and correlation coefficient $(r)$ of the linear expressions between the ultrasound signal attenuation of different storage temperatures, after $1,2,3$ and 4 weeks of storage

\begin{tabular}{llll}
\hline Time (weeks) & Slope value $A$ & Intercept value $B$ & Correlation coefficient $(r)$ \\
\hline 1 & 0.07 & 1.49 & 0.917 \\
2 & 0.13 & 1.43 & 0.931 \\
3 & 0.12 & 1.62 & 0.939 \\
4 & 0.25 & 1.45 & 0.979 \\
\hline
\end{tabular}


method could be used as a nondestructive firmness measurement technique during low-temperature storage. When the fruit were transferred to room temperature, the firmness and ultrasonic attenuation continued to change in the same directions but much faster than those of the control group, which had been stored at room temperature. Statistical analysis shows good correlation between firmness changes during the ripening process and ultrasonic attenuation measurements for different samples of fruit, when their respective low-temperature storage histories (the time and the temperature) were taken into account. More basic measurements and analyses are required to take account of differing balances among the storage conditions, since these might influence the ultrasonic measurement results.

\section{References}

Berger, S., Luza, J., Peralta, L., 1982. Storage of Fuerte and Hass avocados. Proc. Am. Soc. Hortic. Sci. Trop. Reg. 22, $30-39$.

Bleinroth, E., Zuchini, A., Pompeo, R., 1976. Determination of the physical and mechanical properties of avocado varieties, and their storage at low temperatures. Contanea Inst. Technol. Aliment 7, 29-81.

Chen, P., McCarthy, M.J., Kauten, Y., Sarig, Y., Han, S., 1993. Maturity evaluation of avocados by NMR methods. J. Agric. Eng. Res. 55, 177-187.

Galili, N., Schmulevich, I., Benichou, N., 1998. Acoustic testing of avocado for fruit ripeness evaluation. Trans. ASAE 41, 399-407.
Krautkramer, J., Krautkramer, H., 1990. Ultrasonic Testing of Materials. Springer-Verlag, Heidelberg, Germany.

Lewis, C.E., 1978. The maturity of avocados-a general review. J. Sci. Fd. Agric. 29, 866-875.

Mizrach, A., Flitsanov, U., 1995. Predicting avocado shelf life by an ultrasonic nondestructive method. Acta Hortic. 421, $111-119$.

Mizrach, A., Galili, N., Rosenhouse, G., 1989. Determination of fruit and vegetable properties by ultrasonic excitation. Trans. ASAE 32, 2053-2058.

Mizrach, A., Galili, N., Rosenhouse, G., 1994. Method and a system for nondestructive determination of quality parameters in fresh produce. Israel patent no. 109406. USA patent no. 5,589,209 (December 31, 1996). French patent application no. 9504869 (April 24, 1995).

Mizrach, A., Galili, N., Gan-Mor, S., Flitsanov, U., Prigozin, I., 1996. Model of ultrasonic parameters to assess avocado properties and shelf life. J. Agric. Eng. Res. 65, 261-267.

Mizrach, A., Flitsanov, U., Akerman, M., Zauberman, G., 2000. Monitoring avocado softening in low-temperature storage using ultrasonic measurements. Comput. Electron. Agric. 26 (2), 199-207.

OECD Standards, 1995. International Standardization of Fruit and Vegetables - Avocado. Organization for Economic Co-operation and Development, OECD Publications, Paris, France.

Peleg, K., Ben-Hanan, U., Hinga, S., 1990. Classification of avocado by firmness and maturity. J. Texture Stud. 21, $123-139$.

Schmilovitch, Z., Hoffman, A., Egozi, H., Albatzri, R., Degani, C., 1997. Determination of avocado maturity by near-infrared spectrometry. The 3rd International Symposium on Sensors in Horticulture, Tiberias, Israel.

Zauberman, G., Fuchs, Y., 1981. Effect of wounding on 'Fuerte' avocado ripening. HortScience 16, 496-497.

Zauberman, G., Jobin-Decor, M.P., 1995. Avocado (Persea americana Mill.) quality changes in response to low-temperature storage. Postharvest Biol. Technol. 5, 235-243.

Zauberman, G., Schiffman-Nadel, M., Yanko, U., 1977. The response of avocado fruits to different storage temperatures. HortScience 12, 353-354. 